\title{
Global exchange and accumulation of non-native plants
}

\begin{abstract}
Mark van Kleunen ${ }^{1}$, Wayne Dawson ${ }^{1}$, Franz Essl ${ }^{2}$, Jan Pergl ${ }^{3}$, Marten Winter ${ }^{4}$, Ewald Weber ${ }^{5}$, Holger Kreft $^{6}$, Patrick Weigelt ${ }^{6}$, John Kartesz ${ }^{7}$, Misako Nishino ${ }^{7}$, Liubov A. Antonova ${ }^{8}$, Julie F. Barcelona ${ }^{9}$, Francisco J. Cabezas ${ }^{10}$, Dairon Cárdenas ${ }^{11}$, Juliana Cárdenas-Toro ${ }^{12,13}$, Nicolás Castaño ${ }^{11}$, Eduardo Chacón ${ }^{2,14}$, Cyrille Chatelain ${ }^{15}$, Aleksandr L. Ebel ${ }^{16}$, Estrela Figueiredo ${ }^{17,18}$, Nicol Fuentes ${ }^{19}$, Quentin J. Groom ${ }^{20}$, Lesley Henderson ${ }^{21}$, Inderjit ${ }^{22}$, Andrey Kupriyanov ${ }^{23}$, Silvana Masciadri ${ }^{24,25}$, Jan Meerman ${ }^{26}$, Olga Morozova ${ }^{27}$, Dietmar Moser ${ }^{2}$, Daniel L. Nickrent ${ }^{28}$, Annette Patzelt ${ }^{29}$, Pieter B. Pelser ${ }^{9}$, María P. Baptiste $^{12}$, Manop Poopath $^{30}$, Maria Schulze $^{31}$, Hanno Seebens ${ }^{32}$, Wen-sheng Shu ${ }^{33}$, Jacob Thomas ${ }^{34}$, Mauricio Velayos ${ }^{10}$, Jan J. Wieringa ${ }^{35,36} \&$ Petr Pyšek $^{3,37,38}$
\end{abstract}

All around the globe, humans have greatly altered the abiotic and biotic environment with ever-increasing speed. One defining feature of the Anthropocene epoch ${ }^{1,2}$ is the erosion of biogeographical barriers by human-mediated dispersal of species into new regions, where they can naturalize and cause ecological, economic and social damage ${ }^{3}$. So far, no comprehensive analysis of the global accumulation and exchange of alien plant species between continents has been performed, primarily because of a lack of data. Here we bridge this knowledge gap by using a unique global database on the occurrences of naturalized alien plant species in 481 mainland and 362 island regions. In total, 13,168 plant species, corresponding to $3.9 \%$ of the extant global vascular flora, or approximately the size of the native European flora, have become naturalized somewhere on the globe as a result of human activity. North America has accumulated the largest number of naturalized species, whereas the Pacific Islands show the fastest increase in species numbers with respect to their land area. Continents in the Northern Hemisphere have been the major donors of naturalized alien species to all other continents. Our results quantify for the first time the extent of plant naturalizations worldwide, and illustrate the urgent need for globally integrated efforts to control, manage and understand the spread of alien species.

The magnitude of impacts caused by alien species on native biota and human societies is increasing rapidly ${ }^{3}$. However, our knowledge of the global spread and distribution of naturalized species (that is, alien species that form self-sustaining populations in new regions ${ }^{4,5}$ ) is still very limited. Nevertheless, there are many presumptions about the distributions and patterns of spread of alien species. For example, it has frequently been suggested that Old World species have spread more widely outside their native ranges than New World species, owing to human colonization history or intrinsic evolutionary superiority ${ }^{6,7}$. It has also been suggested that islands have more alien species than mainland areas, among others because of unfilled niche space on islands $s^{7,8}$ or, as shown for birds, a higher introduction effort ${ }^{9}$. Although these hypotheses have been tested for some parts of the world $^{9,10}$, global tests are still lacking.

Scientific and societal concerns about alien species have led to improved documentation of their distributions, and inventories have become available for many regions ${ }^{11}$. Many of these inventories are still incomplete, especially for megadiverse taxonomic groups that are difficult to survey, such as invertebrates and microorganisms, and for less well-surveyed regions. However, vascular plants are well documented because of long histories of exploration. Recently, there have been several major efforts to combine inventories of alien species for large geographical regions (for example, Delivering Alien Invasive Species Inventories for Europe (DAISIE; http://www.europe-aliens. $\operatorname{org} /)$ ) and for those considered to be the most problematic invaders globally ${ }^{12}$. However, a global database of the distribution of all naturalized alien plant species had not yet been built. Such data are essential for understanding global naturalization patterns and their underlying processes, reporting biodiversity status in terms of essential biodiversity variables ${ }^{13}$, and informing environmental managers across political borders via early warning systems.

Here, we present an analysis of naturalized vascular plant species in 843 non-overlapping regions (countries, federal states, islands) covering $\sim 83 \%$ of the Earth's land surface (Fig. 1). We used a novel database, Global Naturalized Alien Flora (GloNAF), combined with data on the origins of the naturalized species and estimates of the numbers of native species per continent, to assess (1) which continents have accumulated the largest naturalized floras, and (2) which have been the major donors of naturalized alien plant species to other parts of the world.

\footnotetext{
${ }^{1}$ Ecology, Department of Biology, University of Konstanz, Universitätsstrasse 10, D-78464 Konstanz, Germany. ${ }^{2}$ Division of Conservation, Vegetation and Landscape Ecology, University of Vienna,

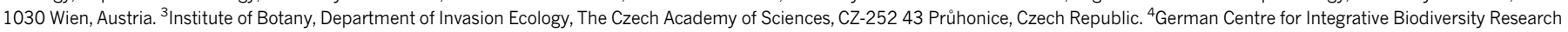
(iDiv) Halle-Jena-Leipzig, Deutscher Platz 5e, D-04103 Leipzig, Germany. ${ }^{5}$ Institute of Biochemistry and Biology, University of Potsdam, D-14469 Potsdam, Germany. ${ }^{6}$ Biodiversity, Macroecology \&

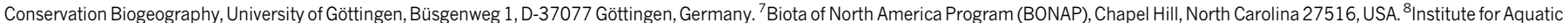

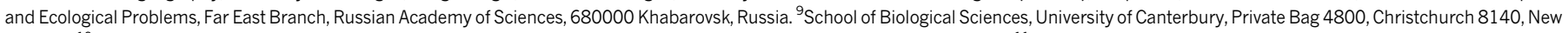

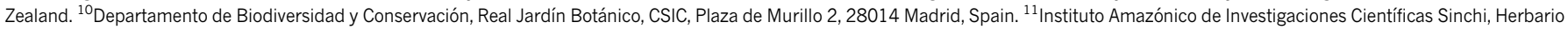

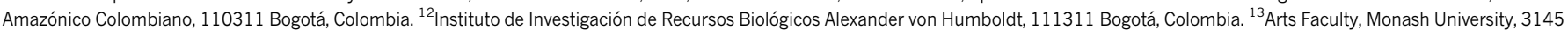

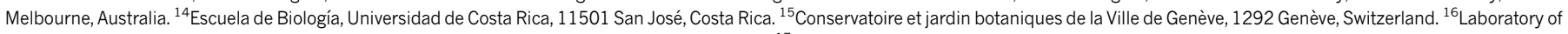

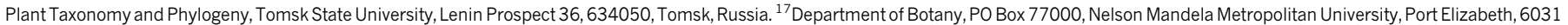
South Africa. ${ }^{18}$ Centre for Functional Ecology, Departamento de Ciências da Vida, Universidade de Coimbra, $3001-455$ Coimbra, Portugal. ${ }^{19}$ Facultad de Ciencias Forestales, Instituto de Ecología y

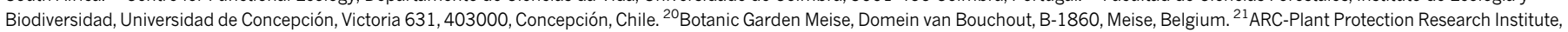

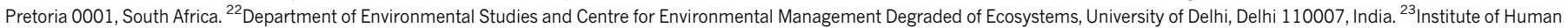

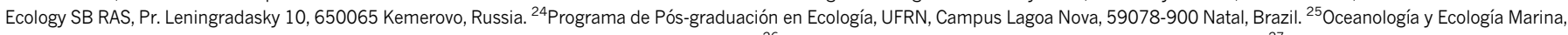
Facultad de Ciencias, Universidad de la República, Iguá, 4225, CP 11400, Montevideo, Uruguay. ${ }^{26}$ Belize Tropical Forest Studies, PO Box 208 , Belmopan, Belize. ${ }^{27}$ Institute of Geography RAS,

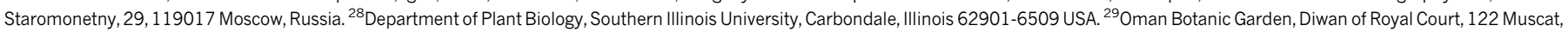

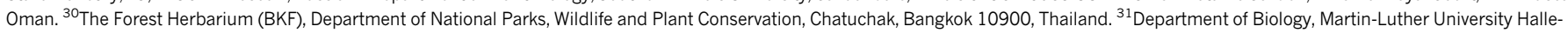
Wittenberg, D-06108 Halle, Germany. ${ }^{32}$ Institute for Chemistry and Biology of the Marine Environment, University of Oldenburg, Carl-von-Ossietzky Straße 9-11, D-26111 Oldenburg, Germany.

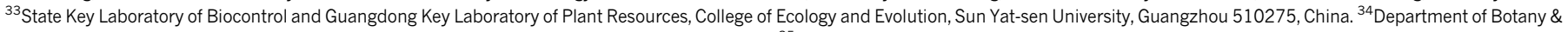
Microbiology, College of Science, King Saud University, PO Box 2455, Riyadh 11451, Saudi Arabia. ${ }^{35}$ Naturalis Biodiversity Center (Botany section), Darwinweg 2, 2333 CR Leiden, the Netherlands.

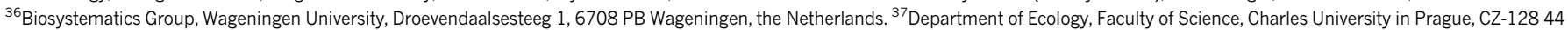
Viničná 7, Prague 2, Czech Republic. ${ }^{38}$ Centre for Invasion Biology, Department of Botany and Zoology, Stellenbosch University, Matieland 7602 , South Africa.
} 


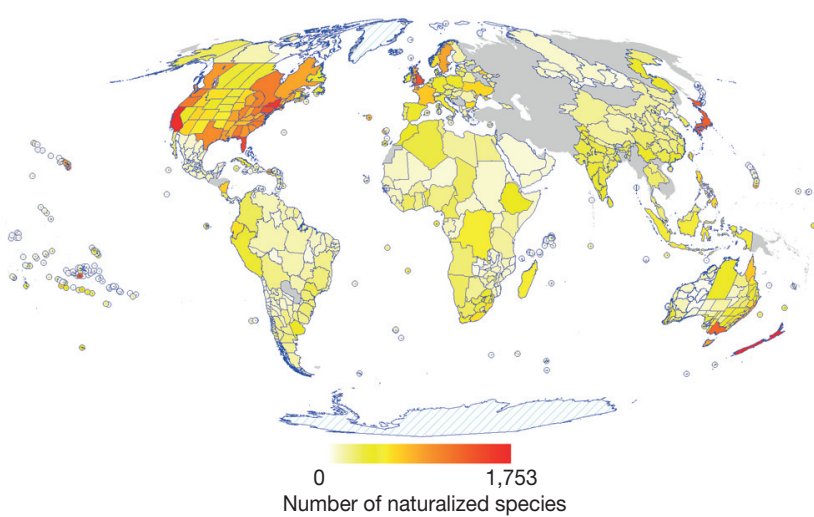

Figure $1 \mid$ Naturalized vascular plant species in the 843 regions covered by the GloNAF database. The heat-map colours correspond to the number of naturalized species in each of the regions (including 362 island regions). Areas permanently covered by ice sheets are indicated in hatched cyan. Grey areas indicate regions lacking naturalized plant data. To allow comparisons between the sizes of the GloNAF regions, we used a Mollweide equal-area projection. However, to increase the visibility of small islands and island groups on the map, they are represented by circles.

We found that at least 13,168 vascular plant species have become naturalized in at least one of the 843 regions (including 362 islands) (Fig. 1). As there were no data available for approximately $17 \%$ of the Earth's land area, particularly in temperate Asia (Fig. 1), and some of the regional inventories used might not be fully comprehensive, the actual number is likely to be even higher. This means that at least 3.9\% of all currently known vascular plant species on Earth $(n=337,137$; http://www.theplantlist.org/) have become naturalized outside their natural ranges as a result of human activity. With continuing globalization and increasing international traffic and trade, it is very likely that more species will be introduced outside their natural ranges and naturalize.

To assess which continents have accumulated the highest number of naturalized species, we assigned each of the GloNAF regions to the nine major biogeographically defined areas recognized by the Biodiversity Information Standards (also known as the Taxonomic Databases Working Group (TDWG) ${ }^{14}$; Fig. 2a). Since the areas of the TDWG continental scheme (further referred to as TDWG continents) differ significantly in size, we created accumulation curves of naturalized species to allow comparisons of the number of naturalized plants per continent for equal areas ${ }^{15}$. When ignoring differences in total area, North America has the highest cumulative number of naturalized species ( $n=5,958)$, followed by Europe $(n=4,140$; Fig. $2 b$ ). Although the rich naturalized floras of these continents could partly reflect a higher sampling intensity in these continents, it is likely that they also reflect a higher introduction effort. Both continents have dominated international trade for centuries, and many plants have been intentionally introduced from other continents for agricultural and horticultural purposes ${ }^{16,17}$.

Although North America has a longer history of European colonization than Australasia, it received only slightly more naturalized species from outside the continent $(3,513)$ than the latter $(3,371$; Fig. 2c). However, Australasia has even more such extra-continental species than North America when taking into account area differences (Fig. 2c). One possible explanation is that Australia's long biogeographical isolation and drying climate have resulted in a native flora that is phylogenetically distinct ${ }^{18}$, but not well-adapted to exploit the novel habitats created by European settlers. These new habitats have instead been occupied by many incoming alien plant species.

When only extra-continental arrivals are considered, Europe drops to fifth position, just behind Africa (Fig. 2c). Thus, although many plants from other continents have been introduced into Europe ${ }^{17,19}$, few of them have naturalized. One explanation might be that plants a

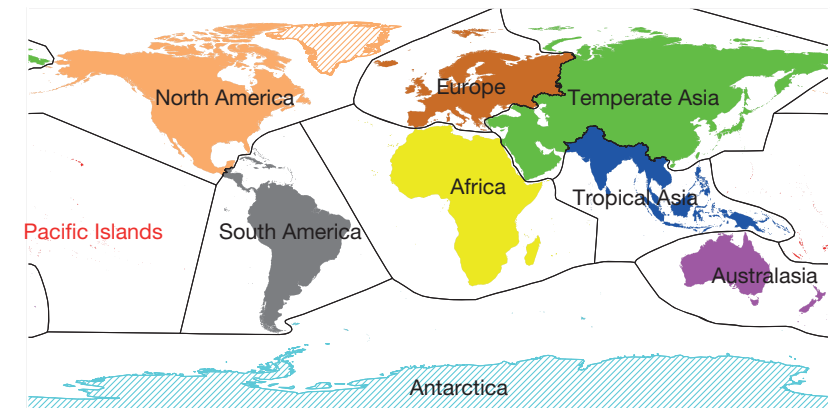

b

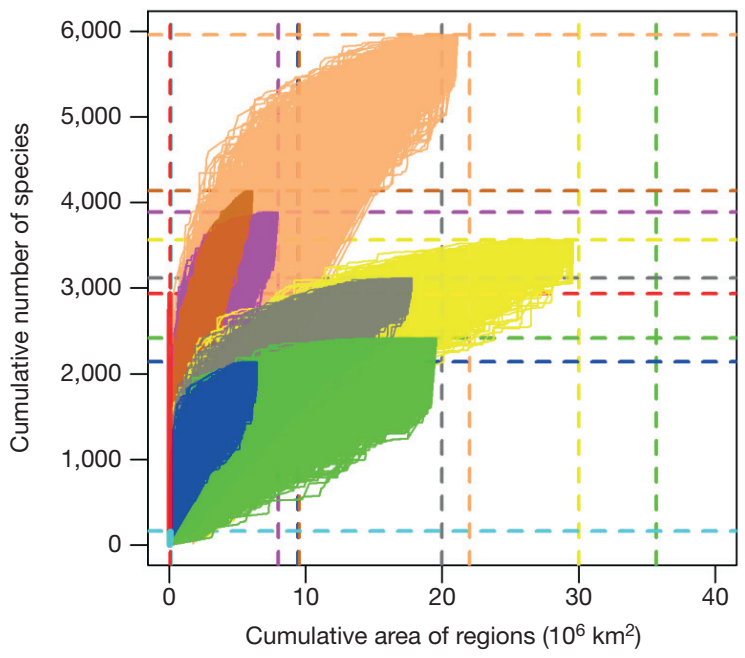

c

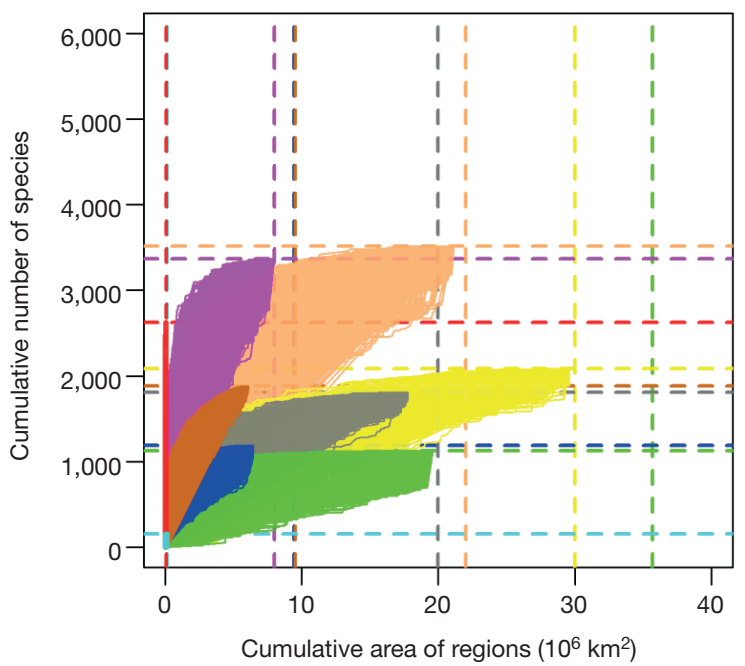

Figure $2 \mid$ Naturalized species-accumulation curves for the major biogeographical areas. a, Map of the nine TDWG continents. Hatched areas indicate major permanent ice sheets. $\mathbf{b}$, Naturalized species-accumulation curves (1,000 random draws) for each of the nine continents. c, Same as $\mathbf{b}$ but here naturalized species are restricted to extra-continental aliens only. The colours in $\mathbf{b}$ and $\mathbf{c}$ correspond to the colours of the continents in $\mathbf{a}$. Vertical and horizontal dashed lines mark the total area of the continent and its total number of naturalized plants, respectively. To increase visibility, thicker lines were used for Pacific Islands and Antarctica.

that spread through Europe with agriculture several thousand years ago (so-called archaeophytes), and European species that naturalized within the continent more recently, have already occupied many of the vacant niches, preventing many extra-continental species from naturalizing. In addition, extra-continental species might be relatively maladapted to the human-dominated environments in Europe, compared with species already present there, which have a longer evolutionary history of growing in these environments ${ }^{6}$. 
The Pacific Islands show the steepest increase in cumulative number of naturalized species with area (Fig. 2). Therefore, our data provide the first global test illustrating that oceanic islands harbour more naturalized alien plants than similarly sized mainland regions, a phenomenon that is attributed to the available niche space not being saturated by native species ${ }^{8,20}$ or to a higher number of introductions. Given the high concentration of endemic species on most oceanic islands ${ }^{21}$, the great richness of naturalized species on these islands constitutes a serious threat to global biodiversity.

TDWG continents with large tropical regions (Africa, South America and tropical Asia) have, overall, fewer naturalized alien species than the predominantly temperate continents (North America, Europe and Australasia). This is consistent with previous observations suggesting a higher resistance of tropical regions to the establishment of alien species because of fewer available free ecological niches, faster recovery of vegetation after disturbance or a lower introduction rate $e^{7,22,23}$. Temperate Asia, in contrast, shows a very low rate of accumulation of naturalized species with area. Unlike other continents, most of temperate Asia has not been colonized by Europeans (http://commons.wikimedia.org/wiki/Atlas_of_colonialism), and large parts of it have only recently opened up to inward movements of people and plants ${ }^{24}$. With the recent rise of China as a major trade partner, we might expect a rapid increase of naturalized species in temperate Asia in the coming decades.

To identify the major donor continents of naturalized alien plant species, we assigned each naturalized species to its native continent(s). On the basis of estimated numbers of native species per continent, one would expect the most species-rich TDWG continents (South America and tropical Asia) to be the main donors of naturalized plant species (Fig. 3a); but they are not. The observed flow of naturalized plant species clearly shows that temperate Asia and Europe are the major donors (Fig. 3b). Although temperate Asia is ahead of Europe in absolute numbers, the observed number of species native to Europe and naturalized elsewhere is $288 \%$ higher than expected, but only $52 \%$ higher than expected for temperate Asia (Extended Data Fig. 1 and Extended Data Table 1). Furthermore, North America is also overrepresented, with 57\% more species donated than expected (Extended Data Fig. 1). In contrast, the TDWG continents that are largely in the Southern Hemisphere are all underrepresented as donors (Extended Data Fig. 1).These results are robust against potential over- or underestimates of the number of native species per continent (see Extended Data Table 1 for a sensitivity analysis). This suggests that the traditionally acknowledged Old World versus New World dichotomy in

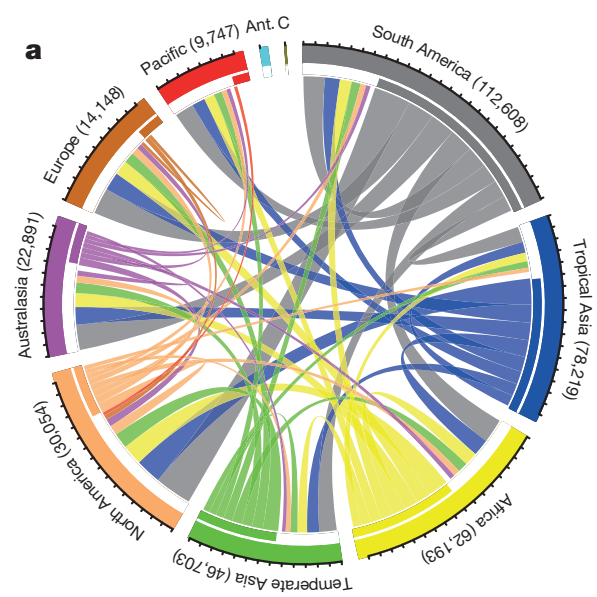

Figure 3 Flows of naturalized alien plant species among the TDWG continents. a, Expected flows (medians of 999 random draws) of naturalized species on the basis of estimated numbers of native species (in brackets). b, Observed flows of naturalized species. The continents are ordered according to decreasing importance as sources. Only the $50 \%$ most important flows are biological invasions ${ }^{6,7}$ needs to be replaced by a Northern Hemisphere versus Southern Hemisphere dichotomy for the donor continents of naturalized alien plants globally. Darwin ${ }^{25}$ suggested that Northern Hemisphere species, as a consequence of a more competitive evolutionary history, are intrinsically better competitors than Southern Hemisphere species, and that this could explain their naturalization success. To determine whether this is indeed the case requires further research. Nevertheless, the fact that the Southern Hemisphere is currently underrepresented as a donor might also indicate that the southern continents still harbour many species that could potentially spread to northern continents when given the chance.

For six of the nine TDWG continents, the observed intra-continental flows were larger than expected (Fig. 3 and Extended Data Fig. 1). Because of the shorter distances, intra-continental propagule pressure can be assumed to have been larger, and because of environmental similarity, subsequent naturalization chances are higher for intracontinental alien species ${ }^{26}$. Notable exceptions with fewer than expected intra-continental naturalizations were South America and tropical Asia. We argue that because many species from these continents have restricted ranges-reflected in relatively high levels of regional endemism ${ }^{21}$ - species from tropical Asia and South America are less likely to have been dispersed outside their native ranges.

The recently compiled GloNAF database has enabled the most comprehensive analysis so far of the global distributions of naturalized alien plant species, and provides the first robust estimates of the flows of naturalized plant species worldwide. We reveal striking differences within and among continents in the sizes of their naturalized alien floras, rates of accumulation of naturalized species with respect to area, and relative importance as exporters of naturalized species. Humans have strongly shaped the geographical composition and global distribution of alien plants among the World's continents, with the Northern Hemisphere being the major donor. The Pacific Islands and Australasia harbour the highest numbers of naturalized alien species, given their sizes and the extent of naturalization of species from other continents. The GloNAF database and the robust large-scale patterns we reveal here provide a vital foundation for testing fundamental hypotheses to understand plant naturalization better. For example, when combined with native plant inventories and phylogenetic data, the database will allow quantification of the degree of global floristic homogenization and tests to determine whether naturalized species are more closely or more distantly related to native species ${ }^{25}$. In addition, the global baseline data of plant naturalizations provided here might contribute an essential biodiversity variable needed to monitor

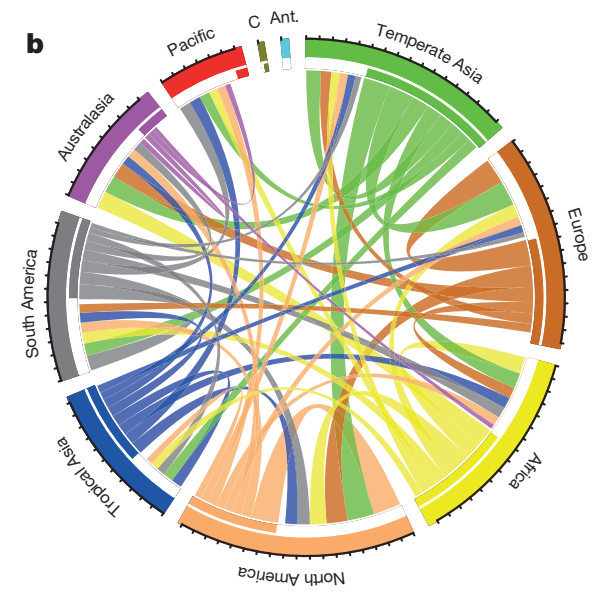

shown. Ant., Antarctica ( $n=293$ native species); C, only known from cultivation or novel hybrids ( $n=97$ species). Each tick along the outer circle corresponds to 1,000 species. Left (white) parts of inner bars along the circle represent flows of imported species; right (coloured) parts represent exported species. 
changes in global biodiversity ${ }^{13}$, and can inform evidence-based management of alien species.

Online Content Methods, along with any additional Extended Data display items and Source Data, are available in the online version of the paper; references unique to these sections appear only in the online paper.

Received 8 April; accepted 14 July 2015.

Published online 19 August 2015.

1. Steffen, W., Grinevald, J., Crutzen, P. \& McNeill, J. The Anthropocene: conceptual and historical perspectives. Phil. Trans. R. Soc. A 369, 842-867 (2011).

2. Lewis, S. L. \& Maslin, M. A. Defining the Anthropocene. Nature 171, 171-180 (2015).

3. Simberloff, D. et al. Impacts of biological invasions: what's what and the way forward. Trends Ecol. Evol. 28, 58-66 (2013).

4. Richardson, D. M. et al. Naturalization and invasion of alien plants: concepts and definitions. Divers. Distrib. 6, 93-107 (2000).

5. Blackburn, T. M. et al. A proposed unified framework for biological invasions. Trends Ecol. Evol. 26, 333-339 (2011)

6. di Castri, R. in Biological Invasions: a Global Perspective (eds Drake, J. A. et al.) 1-30 (John Wiley, 1989).

7. Lonsdale, W. M. Global patterns of plant invasions and the concept of invasibility. Ecology 80, 1522-1536 (1999).

8. Elton, C. S. The Ecology of Invasions by Animals and Plants Ch. 4, 77-93 (Methuen, 1958).

9. Blackburn, T. M., Cassey, P. \& Lockwood, J. L. The island biogeography of exotic bird species. Glob. Ecol. Biogeogr. 17, 246-251 (2008).

10. Fridley, J. D. Of Asian forests and European fields: eastern U.S. plant invasions in a global floristic context. PLOS ONE 11, e3630 (2008).

11. Richardson, D. M. \& Rejmánek, M. Trees and shrubs as invasive alien species - a global review. Divers. Distrib. 7, 788-809 (2011).

12. Lowe, S.. Browne, M.,Boudjelas, S. \& De Poorter, M. 100 of the World's Worst Invasive Alien Species (The Invasive Species Specialist Group (ISSG), 2000).

13. Pereira, H. M. et al. Essential biodiversity variables. Science 339, 277-278 (2013)

14. Brummit, R. K. World Geographical Scheme for Recording Plant Distributions Edition 2 (Hunt Institute for Botanical Documentation, 2001).

15. Scheiner, S. M. Six types of species-area curves. Glob. Ecol. Biogeogr. 12, 441-447 (2003)

16. Brickell, C. \& Cathey, H. M. American Horticultural Society A-Z Encyclopedia of Garden Plants (DK Publishing, 2004)

17. Cullen, J., Knees, S. G. \& Cubey, H. S. The European Garden Flora (Cambridge Univ. Press, 2011).

18. Crisp, M., Cook, L. \& Steane, D. Radiation of the Australian flora: what can comparisons of molecular phylogenies across multiple taxa tell us about the evolution of diversity in present-day communities? Phil. Trans. R. Soc. Lond. B 359 1551-1571 (2004)

19. Heywood, V. H. \& Sharroc, S. European Code of Conduct for Botanic Gardens on Invasive Alien Species (Council of Europe, 2013).

20. Denslow, J. S. Weeds in paradise: thoughts on the invasibility of tropical islands. Ann. Mo. Bot. Gard. 90, 119-127 (2003).
21. Kier, G. etal A global assessment of endemism and species richness across island and mainland regions. Proc. Natl Acad. Sci. USA 106, 9322-9327 (2009).

22. Rejmánek, M. in Biodiversity and Ecosystem Processes in Tropical Forests (eds Orians, G. H., Dirzo, R. \& Cushman, J. H.) 153-172 (Springer-Kluwer, 1996).

23. Fridley, J. D. etal. The invasion paradox: reconciling pattern and process in species invasions. Ecology 88, 3-17 (2007).

24. Keller, W., Li, B. \& Shiue, C. H. China's foreign trade: perspectives from the past 150 years. World Econ. 34, 853-892 (2011).

25. Darwin, C. On the Origin of Species by Means of Natural Selection, or the Preservation of Favoured Races in the Struggle for Life (John Murray, 1859).

26. Lambdon, P. W. et al. Alien flora of Europe: species diversity, temporal trends, geographical patterns and research needs. Preslia 80, 101-149 (2008).

Supplementary Information is available in the online version of the paper.

Acknowledgements We thank the DAISIE team, the CONABIO team, E. Zykova, J. K. Vinogradova, S. R. Majorov, M. Schmidt, M. Newman, P. Thomas, R. Pooma, S. McCune, S. S. Tjitrosoedirdjo, H. Roy, S. Rorke, J. Danihelka, Z. Barina, A. Zeddam, S. Masciadri, Z. Barina and P. Nowak for data contributions, Z. Sixtová, B. Rüter, E. Mamonova, M. Krick, O. Michels and T. Scheu for digitizing data and internet searches, G. Müller and J. Moat for help with shapefiles, L. Cayuela for help with the R package Taxonstand, and T. Blackburn, A. Meyer and M. Rejmánek for comments on previous versions of the manuscript. M.v.K. and W.D. acknowledge funding by the Deutsche Forschungsgemeinschaft (KL 1866/9-1). F.E. acknowledges funding by the Austrian Climate and Energy Fund (project number KR11ACOK00355, SpecAdapt). J.P. and P.P. were supported by the Centre of Excellence PLADIAS (Czech Science Foundation project number 14-36079G) and long-term research development project RVO 67985939 (The Czech Academy of Sciences). P.P. acknowledges support by Praemium Academiae award from The Czech Academy of Sciences. M.W. and M.S. acknowledge funding from the Helmholtz Centre for Environmental Research (UFZ) and the German Centre for Integrative Biodiversity Research (iDiv) Halle-Jena-Leipzig (DFG FZT 118). P.W. and H.K. acknowledge funding from the Deutsche

Forschungsgemeinschaft (DFG) Free Floater Program in the Excellence Initiative at the University of Göttingen and in the scope of the BEFmate project from the Ministry of Science and Culture of Lower Saxony. H.S. acknowledges support by the German VW-Foundation. F.J.C. and M.V. acknowledge support of the project Flora de Guinea Ecuatorial, 4 (CGL2012-32934). N.F. thanks the Projects ICM 05-002, PFB-23 and Fondecyt Postdoc 3120125. J.T. acknowledges the support of the Research Center of the College of Science, King Saud University, Riyadh, Saudi Arabia.

Author Contributions M.v.K., P.P., W.D., F.E., J.P., E.W. M.W., H.K. and P.W. are the core GloNAF project members, who searched for and coordinated the collection of inventories of naturalized alien plants. M.v.K. and P.P. digitized the inventories and standardized the taxonomic names. J.K., N.M., L.A., J.B., F.C., D.C. J.C.-T., N.C., E.C., C.C. A.E., E.F., N.F., Q.G., L.H., I., A.K., S.M., J.M., O.M., D.M., D.N., A.P.,P.P., M.P.B., M.P., M.S., H.S., W.S., J.T., M.V. and J.W. contributed naturalized plants inventories or other data. M.v.K led the analyses and writing, with major inputs from P.P., W.D., F.E., J.P., M.W., H.K. and P.W., and further inputs from all other authors.

Author Information Reprints and permissions information is available at www.nature.com/reprints. The authors declare no competing financial interests. Readers are welcome to comment on the online version of the paper. Correspondence and requests for materials should be addressed to M.v.K. (mark.vankleunen@uni-konstanz.de). 


\section{METHODS}

Data compilation. No statistical methods were used to predetermine sample size. The GloNAF database includes inventories of naturalized alien plant species (also infraspecific taxa and hybrid taxa) for 843 regions worldwide. The data sources that we used (see Supplementary Information) include naturalized alien plant compendia, national and subnational lists of naturalized alien plant species published in scientific journals, as books or on the internet, as well as books and online compendia of national or subnational floras with information on which species occur in the wild but are not native. Our database also includes unpublished inventories of naturalized alien species that were specifically compiled for the GloNAF database (for example, for the provinces of China and the states of India). We consider those alien species that have established self-sustaining populations without direct human intervention to be naturalized, following refs 4 and 27. The GloNAF database will be fully publicly available after finalizing funded GloNAF projects (Deutsche Forschungsgemeinschaft and Austrian Science Fund FWF), which are due in about 3 years.

As certain regions of the world are more intensively researched than others, it is unavoidable that some of the regional inventories of naturalized alien species are more comprehensive than others. We aimed to include the most comprehensive and most recent regional inventories. Indeed, more than $95 \%$ of the data sources are from the past two decades (see Supplementary Data). Moreover, since some of the original source lists included alien species that are cultivated only or have nonpersistent populations in the wild, we excluded those species whenever such information was provided, or contacted experts of the regional floras to remove species of doubtful naturalization status. Furthermore, for European countries that differentiated between archaeophytes (alien species that came before the year 1492) and neophytes (species that came after the year 1492), we kept only the latter, because the alien status of some species classified as archaeophytes is disputed; moreover, this classification is not available for other regions of the world, and thus would prevent us from achieving a balanced/standardized assessment of naturalized alien species numbers.

To standardize scientific names, each naturalized plant inventory was compared with The Plant List (http://www.theplantlist.org/), the most comprehensive working list of all plant species ${ }^{28}$. This taxonomic standardization was done with the help of the $\mathrm{R}^{29}$ package Taxonstand ${ }^{30}$. For each species, we kept the name accepted by The Plant List. Species that were not found in The Plant List, also not after accounting for spelling differences, were kept in the database using the names as used in the source data. In total, the database includes 13,168 species of which 13,033 are recognized by The Plant List (12,498 as accepted and 535 as unresolved names). The remaining 135 species do not occur in The Plant List, and among those 11 are ornamental cultivars.

For each species in the database, we compiled data on which of the nine regions of the TDWG continental scheme (TDWG continents ${ }^{14}$ ) it was native to, or whether it was known only from cultivation or resulted from hybridization between two alien species or an alien and a native species. Most of the nativerange data were extracted from the World Checklist of Selected Plant Families (WCSP; http://apps.kew.org/wcsp/), and supplemented with data from the Germplasm Resources Information Network (http://www.ars-grin.gov/cgi-bin/ npgs/html/index.pl). For the approximately 4,000 species that were not included in these two major data sources, we retrieved information on the native regions from printed floristic compendia, extensive internet searches and comparisons of their naturalized distributions to their overall distributions in the Global Biodiversity Information Facility (http://www.gbif.org/). Information about native continents was found for 13,070 species, of which 219 are only known from cultivation and 51 are novel hybrids. Many $(5,646)$ species were native to more than one continent. For the few (98) remaining species, we could not find any information on their native ranges.

Each of the 843 regions covered by GloNAF was assigned to one of the nine TDWG continents. We calculated the area of each region while considering only the ice-sheet-free areas of each region, ranging from 0.03 to $2,486,952 \mathrm{~km}^{2}$, with a median of $18,725 \mathrm{~km}^{2}$.

Accumulation of naturalized species per continent. To determine which continent accumulated the highest number of naturalized species for a certain area, we constructed species-accumulation curves ${ }^{15}$ separately for each of the nine TDWG continents. Since choosing a starting region and the order of adding remaining regions to the species-accumulation curves would be arbitrary, we used a random order of regions, and repeated this procedure 1,000 times. Species-accumulation curves were calculated for all alien species and for extra-continental alien species separately. This analysis was done in the R package vegan ${ }^{31}$.
Flows of naturalized alien species among continents. To test whether the observed flows of naturalized species from donor continents to recipient continents were larger or smaller than expected, we compared the observed flows with those based on random draws from the extant global flora. Since no data on the number of native species per TDWG continent exist, we first estimated these numbers by extrapolation of the known native origins of 130,641 accepted vascular plant species in the WCSP (http://apps.kew.org/wcsp/) to the total number of 337,137 accepted species in The Plant List (http://www.theplantlist.org/). Although the WCSP includes quite a large proportion (38.8\%) of all vascular plant species, it does not include all vascular plant families yet, and it might be geographically biased. However, ref. 32 showed that all 52 TDWG level-2 regions, and thus the TDWG continents also, are well represented in the WCSP. Furthermore, our estimates did not deviate much from published estimates we found for some of the continents: our estimate of 62,193 native species for Africa is close to the previously estimated 40,000-60,000 for the African mainland ${ }^{33}$, and the 64,500 species listed in the African Plants Database (http://www.ville-ge.ch/musinfo/bd/ cjb/africa/). Our estimate of 14,148 native species for Europe is slightly higher than the 12,517 native species listed in the Flora Europaea ${ }^{34}$. Our estimate of 30,054 native species for North America is higher than the 21,500 species listed in the Biota of North America Program (http://www.bonap.org/), but the latter does not include species of Mexico. Our estimate of 22,891 native species for Australasia is higher than the 19,324 reported for Australia by the Australian National Herbarium (https:/www.anbg.gov.au/aust-veg/australian-florastatistics.html), but the latter does not cover all parts of Australasia (for example, New Zealand). Therefore, although our estimates of the native species richness of each continent are higher than previous estimates, these differences seem to result mainly from additional regions included in TDWG continents and gaps in the other data sources. Thus our results appear to be realistic proxies for the true numbers of continental species richness.

To obtain the expected flows of species from donor to recipient continents, we first created a species pool with a size equal to that of the extant global vascularplant species pool $(n=337,137)$, in which the proportion of species native to each continent or combination of continents was based on the estimated native species richness of the continents. Then, for each recipient continent, we drew separately a random sample of species from the extrapolated global species pool. The size of the random sample was equal to the number of naturalized alien species observed in the recipient continent. We then recorded the number of randomly drawn species native to each continent or belonging to the pool of species known from cultivation or as novel hybrids. This random-draw procedure was repeated 999 times, and the medians are shown in Fig. 3a. We did this for each recipient continent separately to allow for the fact that a species can be naturalized in more than one continent. If the observed flow of species from a donor continent to a recipient continent was within the upper $2.5 \%$ of the random distribution, we considered the observed flow to be significantly larger than expected by chance; if the observed flow was within the lower $2.5 \%$ of this distribution, we considered the flow to be significantly lower than expected by chance. Since we might have over- or underestimated the native species richness for some continents, we also did a sensitivity analysis by decreasing and increasing the size of the native flora of each continent by $10 \%$ in turn (see Supplementary Information). R syntax for the random draws is available from the corresponding author on request. Flow plots were created using an R syntax adapted from ref. 35.

27. Pyšek, P. et al. Alien plants in checklists and floras: towards better communication between taxonomists and ecologists. Taxon 53, 131-143 (2004).

28. Kalwij, J. M. Review of 'The Plant List, a working list of all plant species'. J. Veg. Sci. 23, 998-1002 (2012).

29. R Core Team. R: a language and environment for statistical computing v.3.1.2 (R Foundation for Statistical Computing, 2014).

30. Cayuela, L. \& Oksanen, J. Taxonstand: taxonomic standardization of plant species names v.1.6 (R Foundation for Statistical Computing, 2014).

31. Oksanen, J. et al. Vegan: community ecology package v.2.0-10 (R Foundation for Statistical Computing, 2013).

32. Joppa, L., Visconti, P., Jenkins, C. N. \& Pimm, S. L. Achieving the convention on biological diversity's goals for plant conservation. Science 341, 1100-1103 (2013).

33. Scholes, R. J. et al. in Africa Environment Outlook 2 Ch. 7, 226-261 (African Ministerial Conference on the Environment and United Nations Environment Programme, 2006).

34. Tutin, T.G., et al. Flora Europaea (Cambridge Univ. Press, 1964-1980).

35. Abel, G. J. \& Sander, N. Quantifying global international migration flows. Science 343, 1520-1522 (2014). 


\section{Recipient continent}

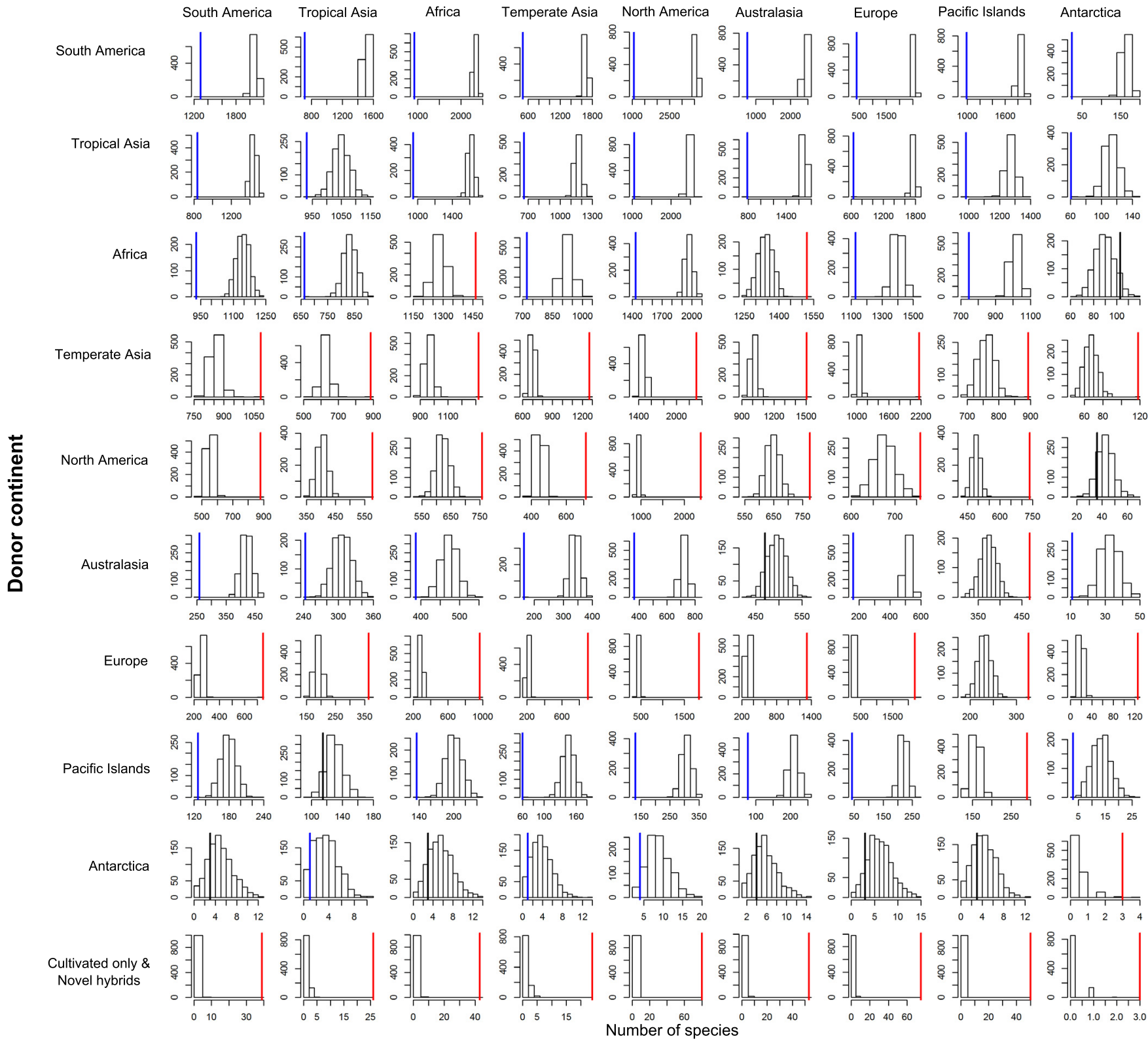

Extended Data Figure $1 \mid$ Observed and expected numbers of naturalized species from each donor TDWG continent in each of the recipient TDWG continents. Histograms of the expected numbers are shown in black open bars, and are based on 999 random draws from the global flora $(n=337,137)$. The observed numbers are shown as vertical lines; blue, significantly fewer observed naturalized species from the source continent than expected (in the lower 2.5 percentile); red, significantly more observed naturalized species than expected (in the upper 2.5 percentile); black, the observed number of naturalized species is within the central $95 \%$ range of the expected numbers. 
Extended Data Table 1 | Results of sensitivity analysis for observed and expected numbers of naturalized species from each donor continent in each of the recipient continents

\begin{tabular}{|c|c|c|c|c|c|c|c|c|c|c|c|c|c|c|c|c|c|c|c|}
\hline & & \multicolumn{18}{|c|}{ Recipient continent } \\
\hline & & \multicolumn{2}{|c|}{ South America } & \multicolumn{2}{|c|}{ Tropical Asia } & \multicolumn{2}{|c|}{ Africa } & \multicolumn{2}{|c|}{$\begin{array}{c}\text { Temperate } \\
\text { Asia }\end{array}$} & \multicolumn{2}{|c|}{ North America } & \multicolumn{2}{|c|}{ Australasia } & \multicolumn{2}{|c|}{ Europe } & \multicolumn{2}{|c|}{ Pacific Islands } & \multicolumn{2}{|c|}{ Antarctica } \\
\hline & & No. & $\mathbf{P}$ & No. & $\mathbf{P}$ & No. & $\mathbf{P}$ & No. & $P$ & No. & $P$ & No. & $\mathbf{P}$ & No. & $\mathbf{P}$ & No. & $P$ & No. & $\mathbf{P}$ \\
\hline \multirow{40}{*}{ 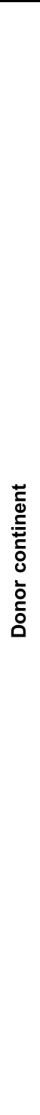 } & & 1293 & & 714 & & 931 & & 501 & & 1070 & & 763 & & 399 & & 993 & & 24 & \\
\hline & South & 2071 & 0.000 & 1509 & 0.000 & 2323 & 0.000 & 1676 & 0.000 & 3568 & 0.000 & 2432 & 0.000 & 2536 & 0.000 & 1834 & 0.000 & 163 & 0.000 \\
\hline & America & 1927 & 0.000 & 1405 & 0.000 & 2166 & 0.000 & 1563 & 0.000 & 3317 & 0.000 & 2263 & 0.000 & 2361 & 0.000 & 1707 & 0.000 & 151 & 0.000 \\
\hline & & 2205 & 0.000 & 1608 & 0.000 & 2474 & 0.000 & 1785 & 0.000 & 3791 & 0.000 & 2588 & 0.000 & 2698 & 0.000 & 1954 & 0.000 & 173 & 0.000 \\
\hline & & 837 & & 931 & & 950 & & 662 & & 1054 & & 787 & & 641 & & 983 & & 61 & \\
\hline & & 1438 & 0.000 & 1050 & 0.000 & 1613 & 0.000 & 1165 & 0.000 & 2473 & 0.000 & 1687 & 0.000 & 1759 & 0.000 & 1272 & 0.000 & 113 & 0.000 \\
\hline & Tropical Asia & 1325 & 0.000 & 967 & 0.000 & 1490 & 0.000 & 1074 & 0.000 & 2283 & 0.000 & 1555 & 0.000 & 1624 & 0.000 & 1175 & 0.000 & 104 & 0.000 \\
\hline & & 1547 & 0.000 & 1128 & 0.095 & 1738 & 0.000 & 1255 & 0.000 & 2662 & 0.000 & 1815 & 0.000 & 1891 & 0.000 & 1370 & 0.000 & 122 & 0.000 \\
\hline & & 930 & & 663 & & 1464 & & 721 & & 1434 & & 1521 & & 1127 & & 747 & & 103 & \\
\hline & Africs & 1144 & 0.000 & 834 & 0.000 & 1285 & 0.999 & 924 & 0.000 & 1968 & 0.000 & 1342 & 0.999 & 1401 & 0.000 & 1013 & 0.000 & 90 & 0.928 \\
\hline & Atrica & 1047 & 0.000 & 764 & 0.000 & 1175 & 0.983 & 849 & 0.000 & 1806 & 0.000 & 1233 & 0.982 & 1285 & 0.000 & 931 & 0.000 & 83 & 0.734 \\
\hline & & 1235 & 0.000 & 901 & 0.000 & 1387 & 0.999 & 1002 & 0.000 & 2126 & 0.000 & 1451 & 0.999 & 1512 & 0.000 & 1095 & 0.000 & 97 & 0.991 \\
\hline & & 1085 & & 886 & & 1320 & & 1272 & & 2315 & & 1505 & & 2166 & & 893 & & 118 & \\
\hline & Temperate & 860 & 0.999 & 626 & 0.999 & 964 & 0.999 & 696 & 0.999 & 1478 & 0.999 & 1010 & 0.999 & 1049 & 0.999 & 761 & 0.999 & 67 & 0.999 \\
\hline & Asia & 784 & 0.999 & 570 & 0.999 & 879 & 0.999 & 632 & 0.999 & 1348 & 0.999 & 920 & 0.999 & 961 & 0.999 & 695 & 0.994 & 62 & 0.999 \\
\hline & & 931 & 0.999 & 680 & 0.999 & 1047 & 0.999 & 755 & 0.999 & 1604 & 0.999 & 1095 & 0.999 & 1142 & 0.999 & 826 & 0.999 & 73 & 0.999 \\
\hline & & 880 & & 577 & & 758 & & 714 & & 2376 & & 775 & & 759 & & 737 & & 36 & \\
\hline & North & 553 & 0.999 & 403 & 0.999 & 621 & 0.999 & 448 & 0.999 & 951 & 0.999 & 648 & 0.999 & 677 & 0.999 & 490 & 0.999 & 43 & 0.111 \\
\hline & America & 502 & 0.999 & 367 & 0.999 & 562 & 0.998 & 407 & 0.999 & 863 & 0.999 & 589 & 0.993 & 613 & 0.811 & 444 & 0.999 & 39 & 0.026 \\
\hline & & 603 & 0.999 & 439 & 0.999 & 675 & 0.999 & 487 & 0.999 & 1037 & 0.999 & 707 & 0.999 & 737 & 0.999 & 534 & 0.999 & 47 & 0.252 \\
\hline & & 259 & & 243 & & 387 & & 165 & & 364 & & 470 & & 163 & & 468 & & 11 & \\
\hline & & 421 & 0.000 & 307 & 0.000 & 474 & 0.000 & 340 & 0.000 & 724 & 0.000 & 496 & 0.105 & 516 & 0.000 & 374 & 0.999 & 33 & 0.000 \\
\hline & Australasia & 381 & 0.000 & 278 & 0.000 & 429 & 0.000 & 309 & 0.000 & 656 & 0.000 & 449 & 0.001 & 467 & 0.000 & 337 & 0.998 & 30 & 0.000 \\
\hline & & 460 & 0.000 & 334 & 0.014 & 514 & 0.011 & 371 & 0.000 & 793 & 0.000 & 540 & 0.863 & 562 & 0.000 & 407 & 0.999 & 36 & 0.000 \\
\hline & & 746 & & 364 & & 966 & & 901 & & 1839 & & 1322 & & 2213 & & 326 & & 126 & \\
\hline & Furne & 261 & 0.999 & 190 & 0.999 & 292 & 0.999 & 211 & 0.999 & 448 & 0.999 & 305 & 0.999 & 319 & 0.999 & 231 & 0.999 & 20 & 0.999 \\
\hline & Europe & 234 & 0.999 & 172 & 0.999 & 264 & 0.999 & 190 & 0.999 & 404 & 0.999 & 276 & 0.999 & 289 & 0.999 & 208 & 0.999 & 18 & 0.999 \\
\hline & & 285 & 0.999 & 207 & 0.999 & 321 & 0.999 & 231 & 0.999 & 489 & 0.999 & 335 & 0.999 & 335 & 0.999 & 253 & 0.999 & 22 & 0.999 \\
\hline & & 127 & & 115 & & 136 & & 60 & & 131 & & 78 & & 43 & & 291 & & 3 & \\
\hline & Pacific & 180 & 0.000 & 130 & 0.069 & 201 & 0.000 & 146 & 0.000 & 308 & 0.000 & 210 & 0.000 & 220 & 0.000 & 158 & 0.999 & 14 & 0.000 \\
\hline & Islands & 162 & 0.000 & 117 & 0.002 & 181 & 0.000 & 131 & 0.000 & 278 & 0.000 & 190 & 0.000 & 198 & 0.000 & 143 & 0.999 & 13 & 0.000 \\
\hline & & 197 & 0.003 & 144 & 0.398 & 221 & 0.000 & 159 & 0.000 & 338 & 0.000 & 232 & 0.000 & 241 & 0.000 & 174 & 0.999 & 15 & 0.001 \\
\hline & & 3 & & 1 & & 3 & & 1 & & 4 & & 4 & & 3 & & 3 & & 3 & \\
\hline & Antarntica & 5 & 0.093 & 4 & 0.022 & 6 & 0.059 & 4 & 0.013 & 9 & 0.015 & 6 & 0.118 & 6 & 0.045 & 5 & 0.136 & 0 & 0.992 \\
\hline & Antarctica & 5 & 0.071 & 3 & 0.014 & 5 & 0.040 & 4 & 0.008 & 8 & 0.007 & 6 & 0.092 & 6 & 0.027 & 4 & 0.105 & 0 & 0.985 \\
\hline & & 6 & 0.144 & 4 & 0.027 & 6 & 0.083 & 5 & 0.018 & 10 & 0.028 & 7 & 0.191 & 7 & 0.071 & 5 & 0.183 & 0 & 0.996 \\
\hline & & 39 & & 26 & & 43 & & 24 & & 80 & & 53 & & 75 & & 50 & & 3 & \\
\hline & Cultivated & 2 & 0.999 & 1 & 0.999 & 2 & 0.999 & 1 & 0.999 & 3 & 0.999 & 2 & 0.999 & 2 & 0.999 & 1 & 0.999 & 0 & 0.997 \\
\hline & only \& novel & 1 & 0.999 & 1 & 0.999 & 2 & 0.999 & 1 & 0.999 & 3 & 0.999 & 2 & 0.999 & 2 & 0.999 & 1 & 0.999 & 0 & 0.996 \\
\hline & hybrids & 2 & 0.999 & 1 & 0.999 & 2 & 0.999 & 1 & 0.999 & 3 & 0.999 & 2 & 0.999 & 2 & 0.999 & 2 & 0.999 & 0 & 0.999 \\
\hline
\end{tabular}

For each combination of two TDWG continents, the table gives the observed number (No.) of species that are native to the donor continent and have become naturalized in the recipient continent in bold

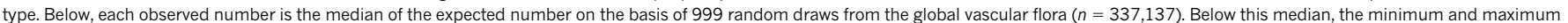

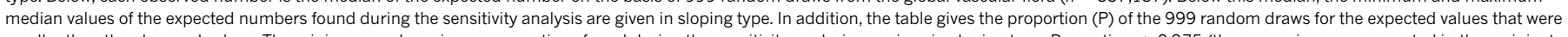

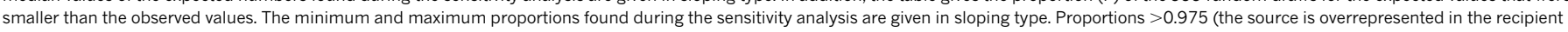
continent) are given in red; proportions $<0.025$ (the source is underrepresented) are given in blue. 